\title{
A direção da utopia: uma leitura do romance Oiobomé, de Nei Lopes
}

\author{
The utopian direction: a reading of the novel Oiobomé, by Nei Lopes \\ La dirección de la utopia: una lectura de la novela Oiobomé, de Nei Lopes
}

Breno Fernandes*

\begin{abstract}
Resumo
Este artigo faz uma crítica do romance juvenil Oiobomé: a epopeia de uma nação, do escritor carioca Nei Lopes (1942-). Partindo do pressuposto de que a obra foi concebida como narrativa de utopia e, ao mesmo tempo, narrativa pedagógica, com vistas a combater o racismo, a crítica mostra que as limitações criadas pela lógica da nação dirimem o tom utópico do romance, possibilitando mesmo que seja lido como uma narrativa de distopia. Pari passu, com base em ideias de Paul Gilroy e, principalmente, de Édouard Glissant a respeito da maneira mais produtiva de, hoje em dia, serem concebidas narrativas utópicas que vislumbrem um mundo onde o racismo e outras desigualdades sociais estejam superadas, chega-se aos conceitos de novo épico e de lógica da relação. As ideias que tais expressões definem são ilustradas pelo confronto entre os universos ficcionais do romance Oiobomé e do filme Pantera Negra, ao final do qual se evidencia por que o primeiro, ao contrário do segundo, não se encaixa nesses conceitos.
\end{abstract}

Palavras-chave: épico, nação, racismo, utopia.

\begin{abstract}
This paper analyses the young adult novel Oiobomé, by Nei Lopes (1942-). We argue that the novel was imagined as both a utopian and a pedagogical narrative, in order to confront racism. The limitations created by the logic of nationalism, however, nullify the utopian tone of the novel, allowing for a dystopian reading of the narrative. This paper highlights Édouard Glissant's concepts of new form of epic and the logic of relation in an attempt to think through the most productive means of creating utopian narratives in the present. These ideas are illustrated by opposing the fictional universes of Oiobomé and the film Black Panther, arguing that the latter fits within Glissant's concepts, while the former does not
\end{abstract}

Keywords: epic, nation, racism, utopia.

\begin{abstract}
Resumen
Este trabajo hace una crítica de la novela juvenil Oiobomé, del escritor brasilero Nei Lopes (1942-). Presuponiendo que la obra fue concebida como una narrativa de utopía y, al mismo tiempo, una narrativa pedagógica, con el objetivo de combatir el racismo, la crítica enseña que las limitaciones creadas por la lógica de la nación disminuyen la fuerza utópica del libro, hasta el punto en que él puede ser leído como una narrativa de distopía. Además, pensando acerca de las maneras más productivas de crear narrativas de utopía hoy día, el trabajo presenta los conceptos de nuevo épico y de lógica de la relación, de Édouard Glissant. Las ideas que tales expresiones definen son ilustradas por la oposición entre los universos ficcionales de Oiobomé y de la película Pantera Negra. Al final, lo que queda en evidencia es que, entre esas dos narrativas, la segunda es aquella que se adecúa a los conceptos de Glissant.
\end{abstract}

Palabras clave: épico, nación, racismo, utopía.

Historicamente, os negros foram reduzidos a objetos discursivos das variadas narrativas com que os Estados-nações que conformam (ou desejam conformar) o Ocidente construíram seu arcabouço simbólico. Seja no campo artístico, científico ou legislativo, é escandaloso olhar para o

\footnotetext{
* Doutorando em Literatura e Cultura na Universidade Federal da Bahia, Salvador, BA, Brasil. (Dorcid.org/0000-0002-26742817. E-mail: brenofernandes@gmail.com
} 
passado recente dessas esferas de produção simbólica e verificar a inexistência de um número significativo de sujeitos negros produzindo obras de arte, teorias e leis, no contexto das instituições legitimadas para tais tarefas. Se, para além da lente do racismo, avaliamos essa ausência de sujeitos também pela lente do gênero, tal como Hooks (1995) o faz no âmbito acadêmico norte-americano, o choque pode mesmo virar horror diante de informações como a de que, pelo menos até o início da década de 1990, as poucas mulheres negras que conseguiam ingressar nas universidades dos Estados Unidos compartilhavam a percepção de serem frequentemente "interrogadas pelos que procuravam determinar se ela[s] era[m] capaz[es] de concluir o trabalho, pensar logicamente, escrever coerentemente" (Hooks, 1995, p. 472). Eis aí um exemplo de abuso psicológico que, sozinho, basta para chamar atenção às grandes dificuldades que homens negros e, principalmente, mulheres negras tiveram para começar a ocupar, nessas instituições que controlam a ordem do discurso, o status de sujeitos.

A representatividade do negro nesses espaços ainda é constrangedoramente pequena, mas está melhor do que jamais esteve, vendo as coisas com algum otimismo. Seu principal desafio, depreendido da leitura de Gomes (2009) e de West (1985), é não se deixar cooptar pelos grupos que historicamente têm dominado essas instâncias de produção simbólica, ficando a favor, em troca de capital social rápido e fácil, da manutenção de práticas discursivas que, em parte, foram elas próprias perpetuadoras da exclusão e da objetificação dos sujeitos negros nesses espaços de construção de narrativas. Nilma Gomes (2009, p. 435), que discute o caso brasileiro, entende que o trabalho mais profícuo do intelectual negro acontece quando ele "problematiza, politiza e tensiona o próprio campo do conhecimento a se abrir para o concurso democrático de diferentes formas de conhecer".

É certo que, de modo geral, a figura do intelectual há muito deixou de ser a do erudito trancafiado em uma biblioteca, isolado do cotidiano do mundo, para não se distrair em sua busca pela Verdade, escrita assim, com letra maiúscula. Hoje em dia, espera-se do intelectual uma postura politicamente engajada na sociedade que o acolhe, a coragem de "desafiar e derrotar tanto um silêncio imposto como a quietude normalizada do poder invisível em todo e qualquer lugar e sempre que possível" (Said, 2004, p. 184). No caso específico dos intelectuais negros, a ênfase que se espera que eles deem ao racismo em seu trabalho - e que muitos efetivamente dão, sem que isso os impeça de tratar com destaque de outras temáticas - não se explica por nenhuma norma. Antes, ocorre pelo amalgamento de dois fatores pelo menos.

Em primeiro lugar, houve a revolução que a chamada virada linguística provocou nas ciências humanas mundo afora, deixando claro que as relações de poder não só se sustentam materialmente, mas também simbolicamente. Nesse contexto, enfatizou-se a natureza política de todo e qualquer discurso, incluídos aqueles que se dizem neutros ou apolíticos. Além do mais, aquilo que não é dito passou a chamar bastante atenção, tornando gritante, no Brasil, a ausência ou escassez de discursos sobre "a experiência afro-brasileira vivida na religiosidade, memória, corporeidade, espaço, tempo, linguagens" (Gomes, 2009, p. 432).

Some-se a isso a observação de Gomes (2009) de que o intelectual negro brasileiro não deixa de ser interpelado pelo tema do racismo pela razão óbvia de que, ao longo de sua vida, invariável e recorrentemente, ele experimenta em seu corpo os efeitos daninhos de uma estrutura social racista. De certo modo, ainda que sua produção intelectual não trate diretamente do racismo na sociedade brasileira, sua própria trajetória nas instituições de produção simbólica, performaticamente, já é um discurso sobre o racismo, pois a pele de uma pessoa negra (ainda) fala antes da boca, como bem apontou Fanon (2008).

Dos três campos de atuação aqui mencionados - o artístico, o científico e o legislativo é sobre o primeiro que este pequeno artigo trata. Em específico, volta-se para o campo literário, e sua motivação em debruçar-se sobre a literatura advém do já mencionado argumento de Gomes (2009), sobre a busca de diferentes formas de conhecimento, em conjunto com a seguinte afirmação de Todorov (2009):

Mais densa e mais eloquente que a vida cotidiana, mas não radicalmente diferente, a literatura amplia o nosso universo, incita-nos a imaginar outras maneiras de concebê-lo e organizá-lo. Somos todos feitos do que os outros seres humanos nos dão: primeiro nossos 
pais, depois aqueles que nos cercam; a literatura abre ao infinito essa possibilidade de interação com os outros e, por isso, nos enriquece infinitamente (Todorov, 2009, p. 23-24)

Considerando que a literatura pode ser um exercício de reinvenção do mundo, como apregoa Todorov (2009), e que a preocupação em "trabalhar com ideias que possam servir de catalisador para a transformação de nossas consciências e nossas vidas" (Gomes, 2009, p. 439) parece ser, ao menos na perspectiva de Gomes (2009), um critério de valoração das atividades dos intelectuais negros, foi com empolgação que, navegando por páginas de internet que tratam da literatura negra produzida no Brasil atualmente, descobri o romance Oiobomé: a epopeia de uma nação, de Nei Lopes. O currículo do autor dá mostras de seu empenho em tratar de temas da negritude. Nascido em 1942, no Rio de Janeiro, Nei Lopes começou a participar da cena cultural do país ainda na década de 1970, quando, depois de abandonar a carreira de advogado, passou a dedicar-se à música, ao samba especificamente, como cantor, compositor e membro de escolas de samba cariocas. ${ }^{1} \mathrm{Na}$ década seguinte, foi a vez da literatura. Lopes começou a escrever proficuamente sobre os povos negros e a diáspora africana e não parou desde então. Entre biografias, crônicas, dicionários, enciclopédias, ensaios, ficção, poesia e textos historiográficos, sua produção bibliográfica já conta com quase 40 obras. $^{2}$ Tudo isso "à margem de títulos e elogios acadêmicos" (Vianna, 2012, p. 2), como foi dito em uma reportagem de $O$ Globo, publicada em meados de 2012. Nela, entre outras declarações, Lopes critica o modus operandi das universidades ("A academia é muito corporativista") e louva o reconhecimento da constitucionalidade das cotas para estudantes negros pelo Supremo Tribunal Federal ("Foi desconstruído todo um edifício de argumentos"). Mas, antes de ter contato com falas como essa, que evidenciam um intelectual interessado em promover deslocamentos na ordem das coisas, a hipótese de que Nei Lopes buscava "a transformação de nossas consciências e nossas vidas" me surgiu lendo a quarta capa de Oiobomé.

Oiobomé é um país fictício fundado no fim do século XVIII pelo ex-escravo Domingo Vieira dos Santos, que, a partir do subúrbio carioca, chegou às terras do Grão-Pará fugindo de represálias por seu suposto envolvimento com os inconfidentes de Vila Rica. Decidido a formar o Estado perfeito, no qual não há criminalidade e a taxa de analfabetismo é igual a zero, Dos Santos se lança numa aventura sem limites em busca de seu ideal. Em sua epopeia, vai enfrentar moinhos para inventar uma nova cultura (Lopes, 2010, quarta capa).

Ora, que perfeito exemplo de exercício de transformação do mundo pela imaginação é uma ficção histórica em que um negro, ex-escravizado, funda um novo país nas Américas! Sobretudo se, em consonância com Mbembe $(2008,2014)$, considerarmos que o movimento que os europeus chamam de modernidade e que nos legou o Estado-nação tem, como outro lado da moeda, o processo de colonização e todos os seus efeitos deletérios, entre eles a escravização e o racismo.

Sendo, ademais, um romance juvenil, a ideia de transformação se potencializa, dada a vontade de pedagogia que faz parte do gênero, isto é, o desejo de fazer com que certos conhecimentos alcancem o sujeito em formação e nele se introjetem, como efeito dos afetos que as narrativas mobilizam em nós. Nesse caso, um dos desejos sobressalentes da obra, entre outros que serão

\footnotetext{
${ }^{1}$ Como músico, descontados as coletâneas e relançamentos, Nei Lopes gravou: A arte negra de Wilson Moreira \& Nei Lopes (1981), Negro mesmo (1983), O partido muito alto de Wilson Moreira \& Nei Lopes (1985), Canto banto: 300 anos de Zumbi (1996), Sincopando o breque (1999), De letra \& música (2000), Celebração (2003), Partido ao cubo (2004), Chutando o balde (2009), Samba de fundamento (2012) e Samba a rigor (no prelo). No âmbito das escolas de samba, foi compositor e membro da velha guarda do Salgueiro e, mais tarde, dirigente da Vila Isabel.

${ }^{2}$ Os livros publicados por Nei Lopes, até 2017, foram: O samba na realidade: a utopia da ascensão social do sambista (1981), Islamismo e negritude (1982), Casos crioulos (1987), Bantos, malês e identidade negra (1988), O negro no Rio de Janeiro e sua tradição musical (1992), Dicionário banto do Brasil (1996), Incursões sobre a pele (1996), 171 - Lapa-Irajá: casos e enredos do samba (2000), Logunedé - santo menino que velho respeita (2000), Zé Keti, o samba sem senhor (2000), Guimabustrilho e outros mistérios suburbanos (2001), Novo dicionário banto do Brasil (2003), Sambeabá: o samba que não se aprende na escola (2003), Enciclopédia brasileira da diáspora africana (2011), Kibátu - o livro do saber e do espírito negro-africanos (2004), Partido-alto, samba de bamba (2005), Dicionário escolar afro-brasileiro (2006), Vinte contos e uns trocados (2006), O racismo explicado aos meus filhos (2007), Dicionário literário afro-brasileiro (2007), Kofi e o menino de fogo (2008), História e cultura africana e afrobrasileira (2009), Mandigas da mulata velha na cidade nova (2009), Oiobomé: a epopeia de uma nação (2010), Nação quilombo (2010), Dicionário da antiguidade africana (2011), Esta árvore dourada que supomos (2011), A lua triste descamba (2012), Contos da colina (2012), Dicionário da hinterlândia carioca (2012), Poétnica (2014), Contos e crônicas para ler na escola (2014), Rio negro, 50 (2015), Dicionário da história social do samba (2015), Dicionário da história da África: séculos VII a XVI (2017) e Nas águas desta baía há muito tempo (2017).
} 
mencionados adiante, parece ser o de argumentar que o racismo, transformado em pilar da construção da nação brasileira, foi prejudicial a esta não só do ponto de vista humanitário, mas também teleológico. Em outras palavras, ao reconstituir os passos que fazem com que Oiobomé, nação amefricana, ${ }^{3}$ chegue ao século 21 com excelentes índices de desenvolvimento, política educacional invejável e o incrível feito de ser pioneira na descoberta de "vacinas contra o câncer, a aids, a dengue e a hepatite C" (Lopes, 2010, p. 223), Lopes (2010) denuncia o custo social da marginalização histórica de negros e de negras, o desperdício de talentos que poderiam contribuir para o bem-estar de toda a população do Brasil e, talvez, para realizar a utopia que ainda parece justificar a nação: a utopia de uma comunidade formada por um "companheirismo profundo, horizontal" (Anderson, 1993, p. 25; tradução nossa). Tal comunidade, se passível de ser construída algum dia, só poderá mesmo existir com base no que Silva (2000) chama de pedagogia da diferença e que consiste "em estimular e cultivar os bons sentimentos e a boa vontade para com a chamada 'diversidade' cultural" (Silva, 2000, p. 8). Para com o outro, se poderia dizer também. Ou ainda: para com a diferença.

É exatamente por desviar dessa pedagogia que Oiobomé, apesar de todos os avanços socioeconômicos, parece estar longe de ser um lugar ideal, por vezes replicando as piores características da tradição política latino-americana, como a tirania. Os argumentos que sustentam essa afirmação se encontram nas seções a seguir, nas quais se comenta a trama do romance com mais detalhes (Seção 2) e se apontam os problemas que limitam a potência transformadora de Oiobomé (Seção 3), antes de serem feitas as considerações finais. Com base na pressuposição de que o romance de Lopes (2010) não é uma paródia, mas de fato uma rapsódia, como está escrito em seu frontispício; um vislumbre de como se poderia ter constituído uma identidade brasileira não excludente ainda no século 19, com vistas a suscitar, no presente, algum abalo em relação a nossos mitos de origem hegemônicos; a ideia central deste artigo é que a utopia narrada em Oiobomé se enreda em uma lógica que faz com que, antes de servir ao engendramento de um futuro sem racismo nem outras desigualdades sociais, acaba por reiterar uma série de elementos da ideologia dominante, herdada do passado de colonização. Em outras palavras, Oiobomé replica, por vezes de forma desastrosa, aquilo que inicialmente busca superar.

Para se compreender por que isso acontece, é preciso conhecer a história desse país em primeiro lugar. Vamos a ela.

\section{A história de Oiobomé}

Tudo começa com um menino. Nobre e - por que não? - afortunado, apesar de sua condição de escravizado. Seu nome é Francisco Domingo Vieira dos Santos, nascido na Freguesia do Irajá, província do Rio de Janeiro, em meados do século 18. Seu pai é jeje, membro da nobreza do reino de Daomé. Sua mãe, iorubá do reino de Oyó, inimigo figadal do Daomé. Por conta mesmo de tal rivalidade, a união dos pais de Domingo teria tudo para ser uma "inconcebível relação" (Lopes, 2010, p. 17). Apesar de se explicar em parte pelos novos laços identitários que a escravização fez nascer do encontro das gentes africanas no Brasil, o caráter extraordinário com que esse amor é narrado parece servir para distinguir Domingo desde seu nascimento.

Com a sorte dos predestinados, apesar de escravizado, o garoto cresce em uma fazenda na qual não se aplicam castigos físicos e onde tem oportunidade de educar-se. Já adulto, na condição de homem livre, comerciante de tino e cidadão interessado nas questões políticas da colônia, conhece por acaso o Tiradentes e participa de alguns encontros dos inconfidentes mineiros, embora não se filie à sua causa. Os motivos do não engajamento de Domingo não ficam explícitos no frisson dos acontecimentos. A posteriori, parece ter pesado mais o fato de o fim da escravidão não ter sido ponto de pauta dos revoltosos. Mas não se pode descartar nem o rancor de ter sido alvo de comentários racistas por parte dos poetas de Minas Gerais, nem o interesse econômico do comerciante, cujo encontro inicial com o Tiradentes tem como tema de conversa justamente o prejuízo que a coroa portuguesa vinha dando ao empresariado brasileiro.

\footnotetext{
${ }^{3}$ Este termo foi tomado de Gonzalez (1988) e será melhor explicado na próxima seção.
} 
Fracassada a Inconfidência Mineira (1789), com medo de que sua proximidade com o Tiradentes o leve à prisão, Domingo foge para Belém - que, é válido lembrar, de 1623 a 1815 fez parte da colônia portuguesa do Grão-Pará e Maranhão, com administração distinta da colônia do Brasil. E, uma vez lá, impelido a ter êxito onde o amigo fracassou, escolhe a ilha de Marajó, o maior arquipélago fluvial do mundo, "para se construir um país livre e em paz" (Lopes, 2010, p. 45). Com o apoio dos bancos franceses, das populações indígenas, dos quilombos, de brasileiros pobres e também dos voduns e de outras entidades metafísicas, Domingo dá à luz a República Vitalista de Oiobomé, a segunda nação livre da América Latina, depois do Haiti. Portanto, a segunda nação cujo poder fora parar nas mãos de membros dos grupos historicamente subalternizados.

Gonzalez (1988) cunhou os termos Améfrica, amefricanidade, amefricano para se desviar da denegação $0^{4}$ do elemento africano na construção da identidade brasileira e, ademais, para tratar de uma identidade étnica transnacional, forjada nas Américas a partir da diáspora e engendradora de "uma intensa dinâmica cultural (adaptação, resistência, reinterpretação e criação de novas formas) que é afrocentrada" (Gonzalez, 1988, p. 76). O conceito se encaixa perfeitamente em Oiobomé, o país fictício de Lopes (2010), e este ainda ajuda aquele a se expandir, na medida em que, ao contrário do que aconteceu em muitas nações americanas, em Oiobomé a presença de populações de culturas pré-colombianas dentro das esferas de poder da nação é significativa desde sua gênese, fazendo com que este país alegorize não só a resistência em relação à escravização, mas também em relação à invasão genocida ocorrida em nosso continente. Oiobomé, em suma, é por excelência uma nação amefricana.

Depois de sua fundação, a narrativa sobre Oiobomé começa a se acelerar. Deixa-se de lado a estrutura clássica do romance, com cenas de ação, ricas em descrições e abundância de discursos diretos, e passam a predominar o tom e o estilo da crônica historiográfica, certamente uma estratégia para dar conta de, em pouco mais de 200 páginas, tratar de quase 200 anos da história do país. "Dos Santos governa, então, meio europeu meio africano, meio presidente meio rei divino" (Lopes, 2010, p. 60). Sendo um marechal-presidente e também a máxima autoridade religiosa, ele consegue "infundir respeito e obediência a seus comandados" (Lopes, 2010, p. 52), mas enfrenta dificuldades para além das fronteiras do Estado. Após a família real portuguesa vir para o Brasil, o cerco sobre Oiobomé cresce, e, desrespeitando as tradições diplomáticas de negociação, os luso-brasileiros sequestram Dos Santos quando ele se dispõe a ter um encontro em busca de acordos. O grande líder oiobomense é enviado para o Rio de Janeiro e acaba morto numa cela na ilha das Cobras, sufocado com cal, como mais tarde o seriam os marinheiros negros que participaram da Revolta da Chibata (1910).

Em seu lugar, chega ao poder um neto e colaborador, Jorge dos Santos, que transforma a república em império, autodeclarando-se o imperador Jorge I. Sua nova constituição, se, por um lado, é liberal a ponto de instituir a poligamia válida para os dois gêneros e também de incentivar a imigração de africanos e seus descendentes, por outro, oficializa o vitalismo religião "dos nossos antepassados, consubstanciada no culto aos ancestrais e aos heróis fundadores, inclusive os de nossos irmãos ameríndios, reforçada pelo culto aos orixás, voduns, oboçons e inquices africanos" (Lopes, 2010, p. 95) - como a religião do Estado. O que gera um conflito religioso que acaba levando Jorge I a ser defenestrado em um golpe civil orquestrado pela Sociedade Egipcíaca, um grupo cristão que enxerga, na bíblia, vínculos hereditários entre os faraós egípcios e a família real israelita, ou mesmo entre aqueles e Jesus.

Jorge I vai para o exílio em Serra Leoa, de onde não mais retorna. Membro da Sociedade Egipcíaca, Elias Faustino torna-se o imperador Faustino III e, com a paixão que tinha pela engenharia egípcia, promove avanços enormes na infraestrutura de Oiobomé. Por ter apenas uma filha, Olufemi, uma "mulherzinha meio índia meio preta" (Lopes, 2010, p. 97), e desejar que ela lhe dê um neto para herdar o trono, Faustino se empenha em encontrar para a moça um marido - especificamente um negro islamizado, porque, em sua visão racista, da qual a filha

${ }^{4}$ Como explica Gonzalez (1988, p. 69), a denegação, em sentido psicanalítico, é o processo no qual o sujeito expõe aquilo que recalca, mas continua na defensiva. No que diz respeito à identidade brasileira, a ideia de mestiçagem, por vezes, parece seguir essa dinâmica da denegação: reconhece-se a matriz africana em nossa cultura ou em nossos corpos (desrecalque da própria negritude) para rapidamente superá-la com o conceito de mestiço, que sombreia o vínculo direto da identidade com a negritude. 
compartilha, só os fulânis, dentre todos os grupos africanos, teriam boas qualidades de sobra, ademais de poder ser úteis às relações exteriores de seu governo, embora não fique claro como.

Apesar de o desejo do imperador Faustino se realizar, ele não chega a conviver com seu herdeiro de sangue malê, pois é assassinado por um assecla, o general Benedito Mundurucu, que descende de netos bastardos de Domingo dos Santos. O crime se dá no início da década de 1830, e sabemos disso porque, logo que Mundurucu se instaura no poder, recuperando o cargo de presidente, no Brasil estoura a Guerra dos Farrapos (1835-45). Em paralelo a essa disputa interna, os brasileiros travam contra os oiobomenses a Grande Guerra com o Brasil, pois aqueles ainda se negam a reconhecer a soberania de Oiobomé.

Nesse mesmo período - enquanto no Brasil se funda o Instituto Histórico e Geográfico Brasileiro (IHGB) e se promove um concurso de monografias acerca da identidade nacional, que premiaria o trabalho do cientista bávaro Carl von Martius (1794-1868), difusor do mito das três raças - em Oiobomé, o debate sobre a natureza da identidade de seus cidadãos toma conta do país. Sempre que este é o assunto em pauta, com humor e ironia, o narrador traz à cena personalidades das ciências humanas e das artes que, a despeito de seus nomes tão evidenciadores de um complexo hibridismo cultural, tais como Xangobunmi dos Santos, JeanPaul Caiapó dos Santos ou Héctor Plaisir dos Santos, defendem apaixonadamente "a essência da alma afro-indígena" (Lopes, 2010, p. 129) de seus compatriotas. Aqueles que alertam sobre os perigos de esse etnocentrismo descambar em racismo são minoria, mas, como em Oiobomé tudo termina relativamente melhor do que no Brasil, já aí, em meados do século 19, quando a sociologia ainda engatinhava, o governo decide criar centros de pesquisa da cultura oiobomense, contemplando também seus componentes europeus, por entender que, sem estudá-los, "'não se pode dimensionar a real importância dessa cultura' [...] [nem] o afastamento de elementos que, 'em nome de um duvidoso progresso', imobilizam as culturas 'de arkhé'” (Lopes, 2010, p. 130-131). Talvez esses mesmos centros venham a ser os responsáveis por, mais tarde, em meados do século 20, influenciar o governo de Oiobomé a pioneiramente adotar políticas afirmativas voltadas para inclusão social da minoria branca.

Por doze anos o presidente Mundurucu fica no poder, até que sofre um atentado terrorista no qual ele e seus ministros são queimados vivos na Casa Verde, o palácio presidencial (um crime jamais solucionado, diga-se de passagem). O deputado Elijah Patajó assume temporariamente o cargo de chefe de Estado, no entanto se aproveita da nova posição para dar um golpe, dissolver o parlamento e ressuscitar o título de imperador, nomeando-se Elijah I. Ele governa o país tirânica e corruptamente por duas décadas, até ser "derrotado por forças democráticas" (Lopes, 2010, p. 144) que levam à presidência um descendente da filha de Faustino III e de seu marido fulâni: Sebastién Mamadu “Da Glória" Jabah.

O governo de Jabah é competente e também próspero, graças à descoberta de minas de diamante em Oiobomé. Todavia "o grande presidente, estadista, idealista e realizador" (Lopes, 2010, p. 161) vê sua popularidade declinar por causa de seu apoio à Coluna Prestes (1925-1927). Ele tem seu mandato interrompido por um golpe que conta com o apoio do Brasil e é encabeçado pelo bispo protestante Tobias Waiwai. Como Tobias I, o novo imperador dá início a uma era marcada pelo fanatismo, pelo populismo e pelo terror aplicado a seus rivais políticos. "Déspota sanguinário e 'pai dos pobres' ao mesmo tempo, ele vai drenando toda a riqueza e a produção do país para negócios misteriosos e escusos que mantém no Brasil e em Caiena" (Lopes, 2010, p. 164).

Só a morte natural de Tobias I o tira do poder. O curioso é que, no instante em que o velho imperador dá seu último suspiro, o país é coberto por nuvens pesadas de chuva, e o aguaceiro que começa a cair na foz do Amazonas é devastador como nunca antes visto, "causando aproximadamente duas mil mortes, deixando milhares de desabrigados e paralisando quase que totalmente as atividades produtivas" (Lopes, 2010, p. 176). Apelidado de dilúvio, o fenômeno, para a ciência, não passou de uma tempestade tropical inusitada. Para a religião, entretanto, foi um susto provocado pelo descontentamento dos ancestrais com os rumos da nação.

Feitas as devidas reverências e consultas espirituais, as coisas parecem voltar aos eixos com a chegada, por sorteio, de Apurinã dos Santos à presidência. Embora seja herdeiro do desonesto Elijah I, é descrito como um ótimo presidente, que dá a Oiobomé uma nova constituição e, finalmente, uma 
base industrial. Mas esse Dos Santos morre precocemente em um acidente de avião, no início da década de 1950. A tragédia cria um já previsível clima de golpe, que só se dissolve quando a deputada Malvina Jackson dos Santos ocupa a cadeira presidencial e convoca uma nova constituinte.

Depois de muito discutir, a assembleia institui que Oiobomé a partir de agora será uma monarquia parlamentarista. "[P]or pressão da bancada feminina, e em atenção à beleza, ao encanto, à pompa e à circunstância que sempre irão cercar o regime monárquico, faz coroar como rainha Sua Majestade Sereníssima Afra-Romana I, nascida Afra-Romana Apinagé dos Santos, elegendo-se como primeira-ministra a vibrante deputada Malvina Jackson dos Santos, companheira de Afra-Romana há mais de quinze anos" (Lopes, 2010, p. 198).

Este é o último governo de Oiobomé que somos dados a acompanhar, antes de um epílogo que traz a narrativa para o tempo presente do leitor. Mas, do pouco que se conta sobre esse matriarcado e de suas líderes, comenta-se que Malvina - ademais de pioneira da aviação civil e desbravadora do Oiobomé profundo, tendo ela própria descoberto ali jazidas de diamante que superam em muito as minas sul-africanas - é uma admiradora da Revolução Cubana (1959) e, talvez motivada por ela, chega à seguinte conclusão:

- Essa porra dessa "democracia representativa" sempre foi uma farsa! E essa merda desse capitalismo não tem nada a ver com a democracia. O princípio da representatividade, caceta, não pode existir entre desiguais!

$[\ldots]$

- O rico não pode representar o pobre, porra! [...] O rico vai legislar sempre de acordo com os seus interesses e "aqui ó" nos pobres. Esse negócio de "democracia representativa" aqui não cola, não, meus camaradinhas. E fim de papo!" (Lopes, 2010, p. 210).

Mas, ao cabo desse pronunciamento em cadeia nacional, o que ela faz não é instalar conselhos à moda soviete ou cubana, os quais, aliás, servem de esteio, não de substituto, do modelo representativo. Jackson simplesmente se limita a dissolver o congresso. " $\mathrm{E}$, finalmente, passa a governar Oiobomé tranquila, ao lado de Sua Majestade Sereníssima" (Lopes, 2010, p. 211).

\section{Oiobomé vs. Wakanda}

Oiobomé, o romance, opera muitas quebras de expectativa no leitor. Tomemos duas questões suscitadas por tais quebras:

(1) Como explicar que uma história que começa com um ex-escravizado sonhando dar dignidade aos subalternizados, no fim das contas, se transforme em uma crônica de formação de oligarquias?

(2) Por que, em uma nação que surge como resposta à escravização, a perda de liberdades individuais prevalece desde o princípio, em diversas esferas da vida, indo desde a proibição de que homens brancos e mulheres negras se casem oficialmente até o uso da internet apenas como "veículo destinado à comunicação e ao estudo" (Lopes, 2010, p. 223); desde uma suspeita afirmação de que "bebidas alcoólicas são naturalmente controladas e consumidas com moderação" (Lopes, 2010, p. 147; grifos nossos) até o estabelecimento de uma religião oficial de Estado?

Uma possível resposta à primeira pergunta pode ser derivada da fusão de teses de base gramsciana e foucaultiana. Lembremo-nos de que o pensamento gramsciano, tal como exposto por Cox (1986), um de seus difusores, apregoa que a manutenção do status quo nas estruturas sociais quase não se dá por imposição, antes ocorrendo por cooptação. O conceito de hegemonia trata justamente disso, de uma relação de poder que vai além da dominação, na qual o polo mais forte não só impõe, mas também faz concessões. Porém tais concessões não chegariam a constituir uma ameaça efetiva à ordem das coisas, uma vez que decorreriam, ao menos em parte, do engendramento prévio de uma consciência coletiva que reflete a ideologia dos próprios detentores da hegemonia. Dito de outro modo, os desejos que moveriam os sujeitos não deixariam de ser, em considerável medida, fruto do regime material e simbólico que molda a estrutura social nas quais esses mesmos sujeitos estão inseridos. Nesse contexto, tais desejos garantiriam a manutenção de tal estrutura. 
Foucault (1996), ao se debruçar sobre a faceta simbólica que domina as estruturas sociais e que ele denominou de regime de verdade, chegou à conclusão de que aí está a fonte de poder. Pode parecer uma afirmação hiperbólica, mas é curioso vê-la respaldada, hoje em dia, até por teses que carregam traços deterministas, concebidas com base no pensamento positivista sobre o mundo, o mesmo que outrora alicerçou a perpetração do racismo e que é tão combatido pelas ideias foucaultianas. Por exemplo, no panorama feito por Harari (2015), no qual são apresentados recentes estudos em paleossociologia, chama atenção uma pesquisa que argumenta que a capacidade de formação de comunidades hierarquizadas de grandes primatas seria limitada à presença física do líder, figura que reiteradamente realizaria ações dignas de um político demagógico, como abraçar os companheiros e carregar os filhotes deles no colo. “ À medida que o número em um bando [...] aumenta, a ordem social se desestabiliza, levando enfim à ruptura e à formação de um novo bando por alguns dos animais" (Harari, 2015, p. 34). O mesmo não acontece com o homo sapiens graças à sua capacidade de criar ficções - uma escolha lexical mais impactante que discurso, convenhamos. A ficção "nos permitiu não só imaginar coisas como também fazer isso coletivamente" (Harari, 2015, p. 33). Podemos compartilhar mitos, e esses "dão aos sapiens a capacidade sem precedentes de cooperar de modo versátil em grande número [...] com um número incontável de estranhos" (Harari, 2015, p. 33). Com essas observações, verifica-se que mesmo o discurso que não se envereda pelos jogos de poder, que ainda defende a neutralidade da ciência, mesmo ele, em alguma medida, reconhece que ter controle sobre a esfera simbólica é ter poder.

Agora, com essa ideia em mente, pensemos na lógica da nação que Anderson (1993) descreve. Ela é a comunidade por excelência do mundo contemporâneo. Ela situa o homem, dá-lhe raiz, senso de pertencimento. A nação é mãe e é útero, é fraternidade e é multiplicação do eu. A nação alija o outro e nos dá o conforto de não ter de lidar com a diferença, que vai sempre suscitar questionamentos sobre nossas convicções identitárias mais firmes. Por ser tudo isso, a nação é capaz de nos cooptar a tal ponto, que, nos últimos séculos, "possibilitou [...] que tantos milhões de pessoas matem e, sobretudo, estejam dispostas a morrer [por ela]" (Anderson, 1993, p. 25, tradução nossa). ${ }^{5}$

Com efeito, as nações existem materialmente. São formadas por instituições, conglomerados urbanos e fronteiras físicas. Mas a nação também é discurso, é uma ficção decorrente da modernidade europeia, aquele mesmo conjunto de práticas e de textos que, como já dito, conforme Mbembe (2008, 2014), justificou a colonização e o racismo. Nesse contexto, a lógica da nação pode bem servir à manutenção de outros elementos da ordem pós-colonial ${ }^{6}$ aos quais ela se conecta, formando a grande teia do regime de verdade que nos captura. O caso de Oiobomé pode ser tomado como ilustração desse enredamento. Embora os povos ameríndios e comunidades quilombolas tenham feito parte da fundação desse país, é intrigante que ali tenha prevalecido, de maneira inquestionável, o modus vivendi capitalista. ${ }^{7}$ Afinal de contas, o capitalismo, outro produto da modernidade europeia, naturaliza um dos piores tipos de desigualdade social jamais praticados: aquele que engessa os indivíduos em classes, minando a possibilidade de que seu status social possa ser determinado pelo que de fato suas aptidões podem oferecer à comunidade. Em uma sociedade capitalista, o status é determinado pela participação dos sujeitos no controle do discurso ou dos meios de produção, ambos os controles quase sempre caminhando juntos e certamente se retroalimentando.

Talvez seja por causa dessa configuração que o narrador, empenhado em nos contar a história de um país, se concentra nas instituições políticas de Oiobomé, ponto de convergência das duas

\footnotetext{
5 "ha permitido [...] que tantos millones de personas maten y, sobre todo, estén dispuestos a morir [...]" (Anderson, 1993, p. 25).

${ }^{6} \mathrm{O}$ pós-colonialismo é uma forma de analisar o mundo, a qual, a despeito do engano a que o termo pós-pode levar, não defende que o legado deixado pela colonização tenha sido superado (Abrahamsen, 2007, p. 113). Efetivamente, o prefixo indica um chamado para se pensar além das premissas e das estruturas que configuram a contemporaneidade e que, ditas universais, são de fato construto do Ocidente; instituições e práticas que foram exportadas aos demais territórios por meio do domínio direto ocidental, exercido entre o final do século XV e meados do século XX, e perpetuadas, hodiernamente, por meio de sua influência política, econômica e militar ao redor do globo. Por isso mesmo há quem diga que a pós-colonialidade é somente outro nome para a globalização das culturas e das histórias ou, ainda, que é uma condição existencial, se se pensa especificamente nos sujeitos contemporâneos, pós-coloniais (Gandhi, 1998, p. 3, p. 126).

${ }^{7}$ Só em meados do século 20, no governo da premiê Malvina Jackson, um chefe de Estado oiobomense expressaria alguma reflexão sobre o tema do capital como prática exploratória, na esteira da Revolução Cubana.
} 
fontes de poder da ordem capitalista, portanto a maior esfera de controle daquela estrutura social. Sua escolha, entretanto, pode ser interpretada como decorrente de cooptação, principalmente quando está narrando acerca do governo absurdamente violento de Tobias I e não se predispõe a lançar holofotes sobre os grupos que lutam para resistir ao tirano. Como as teses de base foucaultiana nos alertam, a historiografia tradicionalmente nos tem contado a versão dos vitoriosos, daqueles que dominam e subjugam. O narrador de Oiobomé começa sua história em contramovimento a essa tradição, mas logo se tem a impressão de que ele muda de rumo.

Uma leitura não categórica dessa guinada do narrador pode considerar que, em uma ordem mundial racista, Oiobomé é invariavelmente um país subalternizado, de modo que a história de seus governantes seria somente uma metonímia da história de uma das poucas nações que proporcionam vida digna aos negros. Com efeito, essa interpretação funcionaria melhor se, afora a disputa territorial com o Brasil, Oiobomé tivesse dificuldades em se fazer reconhecer entre as outras nações, mas isso não acontece. O que é deveras curioso, pois a ordem mundial do universo em que Oiobomé existe tenta emular a nossa, sendo, portanto, uma ordem racista. Todavia somos informados de que, mesmo na primeira metade do século 19, quando o Ocidente estava no auge de seu domínio sobre o mundo e o fantasma do Haiti era uma afronta e uma ameaça a esse domínio, Oiobomé não teve dificuldades em ter sua soberania reconhecida. $O$ que talvez se faça compreender com o dado de que, quando ainda guerreava contra o Brasil, o presidente Dos Santos "consegue o apoio dos Estados Unidos, que também têm interesse econômico e estratégico nas riquezas do mar e do solo na antiga ilha de Marajó" (Lopes, 2010, p. 73). Ou seja: já aí, em sua gênese, Oiobomé estava sendo cooptada pela lógica da nação atrelada ao capital. E parece tê-la acolhido com cedo, em se considerando que, tão logo conseguiu criar um discurso identitário, aquele da essência da alma afro-indígena que culmina na publicação de um ensaio oficial, intitulado "A alma oiobomense", o narrador nos conta que, "[c]om a divulgação dessa obra em nível internacional, Oiobomé passa realmente a existir para o mundo" (Lopes, 2010, p. 130).

A essa altura restam ainda cem anos de história a ser narrada, e, a cada conquista científica ou tecnológica que Oiobomé realiza nesse período, seu prestígio internacional aumenta mais e mais. No entanto esse feito admirável não parece justificar completamente a fixação do olhar do narrador na cadeira de chefe de Estado. No fim das contas, o narrador aparenta mesmo ter sido cooptado pela teleologia da nação, o mesmo discurso que permite aos déspotas que chefiam Oiobomé não se condenarem moralmente por seus atos (descontadas as possíveis psicopatias e perversões). Constatar isso, ter a impressão de que o narrador, ao pôr-se ao lado desses homens hediondos, perdeu de vista o ideal que motivou Domingo dos Santos a fundar Oiobomé, pode ser um golpe duro em sua capacidade de mobilizar a empatia do leitor, sobretudo se este embarcou no livro para buscar detalhes da utopia que o texto da quarta capa promete.

A empatia do leitor também pode se abalar quando o narrador conta, sem críticas, antes se valendo de um tom aparentemente satisfatório, acerca dos cerceamentos de liberdade que permeiam a sociedade oiobomense - alguns deles já mencionados na pergunta (2), no início desta seção. É de estranhar que uma sociedade que se vangloria de ter superado a ideologia do "duvidoso progresso" imobilizador das "culturas 'de arkhé" (Lopes, 2010, p. 131) e que louva sua ancestralidade afro-indígena tenha, por exemplo, um comportamento tão conservador em relação ao álcool ou seja capaz de aprovar, em um governo considerado positivo, como o de Apurinã, uma constituição que determine o seguinte:

que a ordem social do país se baseia na família e prevê a ocupação de todos nos trabalhos agrícolas, industriais e de serviços, exceto de um pequeno grupo de pessoas que terão por tarefa o estudo e a pesquisa. Nas ciências sociais e nas da saúde, essas pesquisas enfatizarão a prevenção, incentivando, por exemplo, campanhas públicas, exames periódicos e vacinação em massa (Lopes, 2010, p. 178).

Ora, onde aí está a arte? Seria uma atividade do setor de serviços, o que a colocaria impreterivelmente sob a égide da economia? Ou os artistas só produziriam como hobby, antes sendo obrigados a se dedicar a uma tarefa produtiva? E por que só um pequeno grupo de pessoas poderá ter a chance de estudar profissionalmente? Para garantir os privilégios de 
uma intelligentsia quando, aparentemente, a capacidade de financiamento da expansão universitária não é um problema para a rica Oiobomé?

Gilroy (2007) comenta que, em meados do século 20, algumas experiências de luta contra o racismo se desviaram para um fundamentalismo que se sentiu fortemente atraído pelo aparato usado pelo fascismo europeu. No fundo dessa motivação estaria a sensação de impotência dada pela estrutura pós-colonial do mundo, impotência suscitadora de "um desejo intenso de resgatar as glórias perdidas do passado africano" (Gilroy, 2007, p. 390) que, por sua vez, acabou por gerar "um arcaísmo complexo tão poderoso a ponto de poder [...] permanecer inteiramente alheio à democracia" (Gilroy, 2007, p. 390). O autoritarismo que marca toda a história de Oiobomé se parece bastante com esse movimento. No romance de Lopes (2010), em nome mesmo da revolução, do bem-estar social, as pessoas não hesitam em abrir mão de seus mecanismos democráticos - a ponto de os muitos golpes jamais terem criado uma rebelião, uma guerrilha ou algo do gênero, e de uma eleição presidencial por sorteio, como sucedeu com a vitória de Apurinã, ser considerada legítima. Com a trama do romance se encerrando com a dissolução do parlamento em benefício do casal real exclusivamente, e um epílogo repleto de loas aos níveis de desenvolvimento de um país onde a população nem sequer tem o direito de escolher livremente como usufruir de seu tempo de lazer - a tirar pela informação de que "a televisão [...] não exibe filmes que ensinem a matar nem programas que imbecilizem; os videogames são exclusivamente educativos" (Lopes, 2010, p. 223) - , com base em tudo isso, não parece infundado ver Oiobomé como uma obra antidemocrática e antiliberal. O país que pretendia emular e atualizar toda a glória dos reinos míticos africanos, cujos fragmentos de cosmogonias que nos chegaram destoam do esquema maniqueísta da metafísica ocidental, afinal, se parece incrivelmente com uma versão contemporânea da República de Platão, onde não há poetas nem nada que corrompa a Virtude.

Pelo menos nos últimos cinquenta anos, temos testemunhado um boom de reflexões que buscam inspiração nas culturas ameríndias e afrodiaspóricas para propor modos de vida cada vez mais alijados do projeto de modernidade ocidental, que tem justamente em Platão um de seus pilares, como nos conta Derrida (1973). Tome-se a oferta de cosmovisões radicalmente ecológica, como aquelas oferecida por Viveiros de Castro (2014) ou por Kopenawa e Albert (2015); ou então a possibilidade de refundar nossas noções de temporalidade, de memória e de conhecimento por meio de uma filosofia da ancestralidade e do corpo, como proposto por Martins (2002) ou por Oliveira (2007) - essas e todas as outras contribuições de crítica à modernidade partem, de certo modo, da constatação de que perseguir os modelos de humano e de sociedade louvados na República de Platão provocou tragédias ambientais, sociais e psíquicas, que nos deram a certeza de termos nos enganado diametralmente quando cogitamos ser este o caminho da utopia. Era de se esperar que em Oiobomé, onde o patrimônio simbólico afro-ameríndio pôde fazer parte da construção de uma comunidade já no século 19, seu povo não tivesse cometido o mesmo engano. Ou, em se considerando o que já foi dito aqui acerca do entrelugar onde Oiobomé se situa, sendo uma nação amefricana completamente inserida no mundo Ocidental, contava-se que ela tivesse ao menos passado pela crise simbólica que o Ocidente enfrentou em meados do século 20, tendo como marco o Maio de 68. O que conferimos na narrativa, entretanto, quando há um salto do início da década de 1960 para o tempo presente, é que os efeitos da crise final da modernidade não ecoaram no arquipélago sul-americano. Por isso, talvez, o último vislumbre que temos de Oiobomé, já no século 21 (a se considerar o grau de desenvolvimento da internet), seja o de um país tão platonicamente virtuoso. Distópico, portanto, em se pensando no zeitgeist em que seu leitor está inserido.

De acordo com Gilroy (2007), o atual modo mais produtivo de pensarmos utopicamente sobre um mundo sem racismo, extirpando os riscos de resvalarmos no protofascismo, teria de partir de um ponto em que os sujeitos "acabe[m] com a sua relação ambivalente com a ideia de 'raça' no interesse de um vir a ser heterocultural, pós-antropológico e cosmopolita" (Gilroy, 2007, p. 391). Ele reconhece como é árduo o seu pedido, haja vista que "o contestado passado imperial e colonial ainda não nos soltou inteiramente de suas garras" (Gilroy, 2007, p. 391). Por isso mesmo emenda: "Não se trata absolutamente de fazer agora uma escolha para tentarmos esgotar e esquecer o que levou tanto tempo para lembrar, ou para simplesmente deixarmos de lado o passado e seus 
traumas" (Gilroy, 2007, p. 391). Seu desejo é encontrar linguagens políticas para o futuro a ser construído, no qual a raça já não encontre mais espaço no plano simbólico. Esse esforço, diz Gilroy (2007), "requer neste momento um juízo cuidadoso quanto a que histórias o nosso presente heterocultural e o nosso futuro cosmopolita deveriam acarretar" (Gilroy, 2007, p. 392).

Oiobomé busca o cosmopolitismo com afinco. Mas resvala nas limitações da lógica da nação mais tradicional, onde não há espaço para a pedagogia da diferença. O romance de Lopes (2010) é, no fim das contas, o que Glissant (2005) bem poderia chamar de um épico do passado feito no presente. Os épicos, ${ }^{8}$ para Glissant (2005, p. 74), são narrativas fundadoras de comunidades, são obras que registram mitos de origem cuja função é "consagrar a presença de uma comunidade em um território, enraizando essa presença, esse presente". Por cumprir essa função, os épicos "são livros que dão segurança à comunidade quanto ao seu próprio destino" (Glissant, 2005, p. 80), que "tranquiliza[m] obscuramente a comunidade sobre a continuidade sem falhas dessa filiação e a partir daí autoriza[m] essa comunidade a considerar como absolutamente sua essa terra tornada território" (Glissant, 2005, p. 74). É a gênese da fronteira, material ou simbólica, que coloca o outro para fora.

Mas Glissant (2005, p. 81) enxerga um duplo movimento nessas narrativas. E comenta: "se examinarmos o Antigo Testamento, a Ilíada, as sagas, a Eneida, logo veremos que [...] 'dentro mesmo' da vocação para o enraizamento, propõem também, imediatamente, a vocação para a errância". Ele chama atenção para isso porque crê que "uma literatura épica nova, contemporânea, começará a despontar a partir do momento em que a totalidade-mundo começar a ser concebida como comunidade nova" (Glissant, 2005, p. 85). Em vez de raiz, rizoma, sugere ele, em perspectiva deleuziana. "A nova literatura épica estabelecerá relação e não exclusão" (Glissant, 2005, p. 85).

Se acompanharmos o pensamento de Glissant (2005), sem perder Oiobomé de vista, o novo épico invariavelmente terá de escapar à lógica da nação, em tudo contrária à totalidade-mundo. Essa sua provocação me faz pensar no recém-lançado Pantera Negra (2018). Esse filme de superherói, baseado no universo ficcional dos quadrinhos da Marvel Comics, teve bastante visibilidade pelo pioneirismo de ser uma grande produção hollywoodiana com elenco majoritariamente formado por atores negros nos papéis principais. É, do ponto de vista da representatividade, uma obra com o mesmo intuito de Oiobomé: uma contribuição à mudança da ordem simbólica; narrativa que supre uma lacuna do imaginário do mundo contemporâneo, ainda racista, cujas histórias, em sua maioria, trazem pessoas negras em papéis que reiteram estereótipos criados ao longo do processo que marginalizou essa parcela da humanidade.

No filme, o verdadeiro nome do super-herói Pantera Negra é T'Challa, e ele é rei de Wakanda, um país africano que, no século XXI, aos olhos do mundo, é uma nação de pobre pastores, mas que, na verdade, é um dos centros de tecnologia mais avançados do mundo, graças a pesquisas feitas com o vibranium, um metal extraterrestre do qual Wakanda dispõe de uma grande jazida e que os antepassados dos atuais wakandenses começaram a manipular, com cedo, com vistas a beneficiar toda a comunidade. A trama principal envereda por questões familiares ligadas ao rei e por uma guerra civil decorrente de uma disputa pelo trono. Em Wakanda, diga-se de passagem, um aspirante a monarca pode ganhar o trono se vence o atual soberano em um combate corpo a corpo. Em meio a tais desafios, que conformam a tradicional jornada do herói, na qual $\mathrm{T}^{\prime}$ Challa deve provar seu valor, chama atenção o final da história, quando ele cede aos argumentos antinacionalistas que tanto sua companheira quanto sua nêmese lhe apresentam e então decide mudar a política secular de esconder do mundo as maravilhas que Wakanda pode fazer com o vibranium, para proteger seu povo de uma potencial investida colonizadora. Assim, em uma das últimas cenas de Pantera Negra, mesmo sob o olhar cético, debochado e preconceituoso de burocratas brancos das Nações Unidas, o rei de Wakanda anuncia que se empenhará em compartilhar o tesouro de seu país com todo o planeta, em prol da melhoria das condições de vida de toda a humanidade. Por se tratar de uma obra também voltada para o público jovem, na qual se pode verificar uma vontade de pedagogia, não parece infundado afirmar que a principal

\footnotetext{
${ }^{8}$ Glissant (2005, p. 94) atenta para que não confundamos a forma épica com a epopeia. Esta seria um gênero textual específico, enquanto aquela, pelo que ele permite inferir ao dizer que "pode passar por outra coisa", seria uma função cabível a vários tipos de texto.
} 
lição de moral de Pantera Negra tem a ver com a superação dos interesses só-da-nação como primeiro passo para a construção de um mundo melhor.

Vale a pena confrontar a decisão de $\mathrm{T}^{\prime}$ Challa com a política externa que adota Malvina Jackson, premiê de Oiobomé, assim que descobre as maiores jazidas de diamante do mundo em seu país, pouco antes de dissolver o congresso nacional:

E, à medida que o sonho diamantífero vai se tornando realidade, é também sob as ordens de Malvina Jackson que o ministro do Abastecimento vai ao Japão e traz de lá informações técnicas que logo transforma em importante programa. Através dele, Oiobomé logo suplanta o Peru como o maior país pesqueiro e exportador de pescado da América do Sul (Lopes, 2010, p. 202).

O que salta à vista são as lógicas distintas que movem os dois grandes Estados negros fictícios. De um lado, Oiobomé está pautado pelo nacionalismo, que é a lógica da exclusão do outro, a lógica da autarquia e da competição econômica. Wakanda, por sua vez, consegue encontrar o caminho para o cosmopolitismo na lógica da relação, na utopia da globalização como possibilidade, para usar uma expressão de Santos (2001). Curiosamente, a situação geográfica de ambos os lugares parece refletir esse comportamento: aquele, uma ilha; este, um território no Chifre da África, berço da humanidade.

De toda sorte, essa gritante discrepância de comportamento dos dois governos só parece corroborar a tese de que o não rompimento com a teia simbólica da nação é um empecilho para que Oiobomé consiga exercer a nova função-épico de que fala Glissant (2005); aquela que depositamos em narrativas com potência para nos fazer visualizar e alicerçar um futuro de superação do racismo e de outras desigualdades sociais. Levando-se em consideração todas as questões discutidas aqui acerca do romance de Lopes (2010), não é surpreendente que, no fim das contas, ele acabe por se assemelhar, em algum grau, ao justo oposto do que almejou ser. Isto é, à medida que a leitura avança, aumenta a sensação de que se está diante, de fato, de uma narrativa de distopia.

\section{Considerações finais}

Ao contrário do que talvez pense o senso comum, a utopia não é um vetor que invariavelmente aponta para o futuro. Efetivamente, seu movimento inicial, impulsionado pela imaginação, é sempre à frente, ainda que preveja zigue-zagues ou serpenteamentos que não deixam de visitar o passado. Mas, como nos mostraram Gilroy (2007) e o próprio Lopes (2010), por vezes esse vetor se enoda cegamente em algum ponto do passado. No caso em tela, ter sido cooptado pela lógica da nação parece ter criado o nó que impede Oiobomé, enquanto proposta de narrativa utópica, de mover-se rumo ao futuro, como Pantera Negra logra fazê-lo ao abandonar essa lógica.

Sucede que o Estado-nação, o principal construto do nacionalismo, é uma das mais poderosas instituições da contemporaneidade a manter a desconfiança, o medo ou a ojeriza como tônica da relação eu/outro. E faz isso ao fundar um espaço que justifica sua legitimidade com promessas de ordem e de segurança que, para se verificarem, dependem de que se apresente o que está do outro lado da fronteira - o outro, inclusive - como perigoso ou caótico. Por melhores que sejam as intenções que, baseando-nos na trajetória de Nei Lopes, pressuponhamos como guias de sua imaginação durante a feitura de Oiobomé, o fato é que a história da tulipa negra do Marajó, da utopia nos trópicos, a história dessa grande ilha não consegue se constituir um épico para o futuro porque se vê enredada nessa estrutura sempre excludente, incompatível com o que vem sendo gestado - ou ao menos sonhado - em nosso tempo, tempo da pedagogia da diferença, tempo de relação.

\section{Referências}

ABRAHAMSEN, Rita (2007). Postcolonialism. In: GRIFFITHS, Martin (Org.). International relations theory for the twenty-first century: an introduction. Londres, Nova Iorque: Routledge. p. 111-122. 
ANDERSON, Benedict (1993). Introducción. In: ANDERSON, Benedict. Comunidades imaginadas: reflexiones sobre el origen y la difusión del nacionalismo. Tradução de Eduardo L. Suárez. Cidade do México: Fondo de Cultura Econômica. p. 17-25.

COX, Robert (1986). Social forces, states and world orders: beyond international relations theory. In: KEOHANE, Robert O. (Org.). Neorealism and its critics. Nova Iorque: Columbia University Press. p. 204-254.

DERRIDA, Jacques (1973). Gramatologia. Tradução de Miriam Schnaiderman e Renato Janini Ribeiro. São Paulo: Perspectiva; Editora da USP, 1973.

FANON, Frantz (2008). Pele negra, máscaras brancas. Tradução de Renato da Silveira. Salvador: EDUFBA.

FOUCAULT, Michel (1996). A ordem do discurso. Aula inaugural no Collège de France, pronunciada em 2 de dezembro de 1970. Tradução de Laura Fraga de Almeida Sampaio. São Paulo: Loyola.

GANDHI, Leela (1998). Postcolonial theory: a critical introduction. Sidney: Allen \& Unwin.

GILROY, Paul (2007). A terceira pedra do sol: humanismo planetário e universalismo estratégico. In: GILROY, Paul. Entre campos: nações, culturas e o fascínio da raça. Tradução de Celia Maria Marinho de Azevedo, André Côrtes de Oliveira, Carlos Marinho da Silva, Patricia de Santana Pinho, Renilson Rosa Ribeiro e Silvana Santiago. São Paulo: Annablume. p. 383-414.

GLISSANT, Édouard (2005). Cultura e identidade. In: GLISSANT, Édouard. Introdução a uma poética da diversidade. Tradução de Enilce do Carmo Albergaria Rocha. Juiz de Fora: Editora da UFJF. p. 71-95.

GOMES, Nilma Lino (2009). Intelectuais negros e produção de conhecimento: algumas reflexões sobre a realidade brasileira. In: SANTOS, Boaventura de Sousa; MENESES, Maria Paula (Orgs.). Epistemologias do sul. Coimbra: Almedina. p. 419-441.

GONZALEZ, Lélia (1988). A categoria político-cultural de amefricanidade. Revista Tempo Brasileiro, Rio de Janeiro, n. 92/93, p. 69-82.

HARARI, Yuval Noah (2015). Sapiens: uma breve história da humanidade. Tradução de Janaína Marcoantonio. Porto Alegre: L\&PM.

HOOKS, bell (1995). Intelectuais negras. Tradução de Marcos Santarrita. Revista Estudos Feministas, Florianópolis, v. 3, n. 2, p. 464-478.

KOPENAWA, Davi; ALBERT, Bruce (2015). A queda do céu: palavras de um xamã yanomami. Tradução de Beatriz Perrone-Moisés. São Paulo: Companhia das Letras.

LOPES, Nei (2010). Oiobomé: a epopeia de uma nação. Rio de Janeiro: Agir, 2010.

MBEMBE, Achille (2008). What is postcolonial thinking? An interview with Achille Mbembe: depoimento. Eurozine. Entrevista concedida a Olivier Mongin, Nathalie Lempereur e Jean-Louis Schlegel. Tradução de John Fletcher. Disponível em: <http://www.eurozine.com/pdf/2008-01-09-mbembe-en.pdf>. Acesso em: 11 set. 2015.

MBEMBE, Achille (2014). Crítica da razão negra. Tradução de Marta Lança. Lisboa: Antígona.

OLIVEIRA, Eduardo (2007). Filosofia da ancestralidade: corpo e mito na filosofia da educação brasileira. Curitiba: Gráfica Popular.

MARTINS, Leda (2002). Performances do tempo espiralar. In: RAVETTI, Graciela; ARBEX, Márcia (Orgs.). Performance, exílio, fronteiras: errâncias territoriais e textuais. Belo Horizonte: UFMG. p. 69-92.

PANTERA Negra (2018). Direção: Ryan Coogler. Produção: Kevin Feige. Roteiro: Ryan Coogler e Joe Robert Cole. Intérpretes: Chadwick Boseman; Michel B. Jordan; Lupita Nyong'o; Danai Gurira; Martin Freeman; Daniel Kaluuya; Letitia Wright; Winston Duke; Angela Bassett; Forest Whitaker; Andy Serkis e outros. [S.I.]: Marvel Studios. (134 min.), son., color.

SAID, Edward (2004). O papel público dos escritores e intelectuais. In: SAID, Edward. Humanismo e crítica democrática. Tradução de Rosaura Eichenberg. São Paulo: Cia. das Letras, 2004. E-book. p. 167-196.

SANTOS, Milton (2001). Por uma outra globalização: do pensamento único à consciência universal. 6. ed. Rio de Janeiro: Record.

SILVA, Tomaz Tadeu da (2000). A produção social da identidade e da diferença. Disponível em: <https://goo.gl/hbkcWZ>. Acesso em: 23 mar. 2018. 
TODOROV, Tzvetan (2009). A literatura em perigo. Tradução de Caio Meira. Rio de Janeiro: DIFEL.

VIANNA, Luiz Fernando (2012). Nei Lopes lança três livros e se firma como um dos maiores artistas e intelectuais do samba. O Globo, Rio de Janeiro, 3 jun. Disponível em: <https://goo.gl/9fWJgQ>. Acesso: 23 mar. 2018.

VIVEIROS DE CASTRO, Eduardo (2014). A inconstância da alma selvagem e outros ensaios de antropologia. São Paulo: Cosac Naify.

WEST, Cornel (1985). O dilema do intelectual negro. Tradução de Braulino Pereira de Santana, Guacira Cavalcante e Marcos Aurélio Souza. Disponível em: <https://goo.gl/kXG3gY>. Acesso em: 23 mar. 2018. 